\title{
PREVALENCE OF SEXUAL DYSFUNCTION AND ITS ASSOCIATED FACTORS IN WOMEN AGED 40-65 YEARS WITH 11 YEARS OR MORE OF FORMAL EDUCATION: A POPULATION-BASED HOUSEHOLD SURVEY
}

\author{
Ana L. R. Valadares, ${ }^{\mathrm{I}}$ Aarão M. Pinto-Neto, ${ }^{\mathrm{I}}$ Maria J. Osis, ${ }^{\mathrm{I}}$ Maria H. Sousa, \\ Lúcia Costa-Paiva, ${ }^{\mathrm{I}}$ Délio M. Conde ${ }^{\mathrm{II}}$
}

doi: $10.1590 / \mathrm{S} 1807-59322008000600012$

\begin{abstract}
Valadares ALR, Pinto-Neto AM, Osis MJ, Sousa MH, Costa-Paiva L, Conde DM. Prevalence of sexual dysfunction and its associated factors in women aged 40-65 years with 11 years or more of formal education: a population-based household survey. Clinics. 2008;63:775-82.
\end{abstract}

OBJECTIVE: To evaluate the prevalence of sexual dysfunction and its associated factors in middle-aged women with 11 years or more of formal education.

METHODS: A cross-sectional, population-based study was carried out using an anonymous, self-response questionnaire. A total of 315 Brazilian-born women, 40-65 years of age with 11 years or more of schooling, participated in the study. The instrument used in the evaluation was based on the Short Personal Experiences Questionnaire. Sexual dysfunction was calculated from the mean score of sexual responsiveness (pleasure in sexual activities, excitation and orgasm), frequency of sexual activities and libido. Sociodemographic and clinical factors were evaluated. Poisson multiple regression analysis was carried out and the prevalence ratios with respective $95 \%$ confidence intervals $(95 \% \mathrm{CI})$ were calculated.

RESULTS: The prevalence of sexual dysfunction was 35.9\% among our study population. Multiple regression analysis showed that sexual dysfunction was positively associated with older age (prevalence ratios $=1.04 ; 95 \% \mathrm{CI}: 1.01-1.07$ ) and with the presence of hot flashes (prevalence ratios=1.37; 95\%CI:1.04-1.80). Having a sexual partner ( $\mathrm{PR}=0.47$; 95\%CI:0.34-0.65) and feeling well or excellent (prevalence ratios $=0.68$; 95\% CI: $0.52-0.88$ ) were factors associated with lower sexual dysfunction scores.

CONCLUSIONS: Sexual dysfunction was present in more than one-third of women that were 40-65 years of age with 11 years or more of formal education. Within that age group, older age and hot flashes were associated with higher sexual dysfunction scores, whereas feeling well and having a sexual partner were associated with better sexuality.

KEYWORDS: Middle-age. Menopause. Vasomotor symptoms. Sexuality. Sexual partner.

\section{INTRODUCTION}

Female sexual function is complex and affected by physical, psychological and social factors. ${ }^{1}$ The prevalence of female sexual dysfunction is high, ranging from $43 \%$ to $88 \%,,^{2,3}$ and it may significantly affect self-esteem and quality of life. Even sexual dysfunction of short duration can create

\footnotetext{
${ }^{I}$ Department of Gynecology and Obstetrics, Universidade Estadual de Campinas - Campinas/SP, Brazil.

II Department of Gynecology and Obstetrics, Universidade Federal de Goiás - Goiânia/GO, Brazil.

Email: anavaladaresf@terra.com.br

Tel.: 55313227.9277

Received for publication on June 23, 2008

Accepted for publication on September 8, 2008
}

frustration and anguish. When chronic, it may lead to anxiety and depression, harm relationships, and cause problems in other aspects of life. ${ }^{1,4}$ Moreover, the clinical effects of sexual dysfunction can be augmented by the intensity of the full range of climacteric symptomatology. ${ }^{5}$ Diseases and factors such as aging, arterial hypertension, smoking and pelvic surgery have been associated with female sexual dysfunction. ${ }^{6}$ Personality, ${ }^{7}$ lifestyle and culture-dependent variables should also be taken into consideration. ${ }^{8}$

Although the epidemiology of male and female sexual function has been investigated in depth, the majority of studies continue to be confined to Europe, the United States (US) and Australasia. ${ }^{9}$ Few studies have been carried out on the sexuality of climacteric women in Latin American 
populations, ${ }^{10-12}$ and data on this subject in women with high school or university educations is particularly sparse.

The aim of this study was to collect information on the prevalence of sexual dysfunction and its associated factors in Brazilian women of 40 to 65 years of age with eleven or more years of formal education.

\section{MATERIALS AND METHODS}

\section{Sample size}

The target population was the female population of Belo Horizonte in the state of Minas Gerais, Brazil, aged 40-65 years, with at least 11 years of formal education, which consisted of 44,313 women in the year 2000 . The necessary minimum sample size for a similar study was calculated to be 377 women, based on the assumption that $43 \%$ of the female population experiences sexual dysfunction, with an expected difference of $5 \%$ between the sample and the general population and a type I error $(\alpha)$ of $0.05 .{ }^{13}$ In the present study, which was limited to women who answered all five questions used to calculate the sexual dysfunction score, the sample size was recalculated to evaluate any possible loss of precision. A sample of 315 women is expected to result in an absolute difference of $5.5 \%$.

\section{Subjects}

This cross-sectional, population-based study was carried out using a self-response questionnaire that was anonymously completed by participants at home between May and September 2005 in the city of Belo Horizonte, Minas Gerais, Brazil. For the purposes of this study, the municipality of Belo Horizonte was stratified into nine regions. From these regions, 18 weighted areas (WA) were randomly selected. The weighted area consisted of a geographical area that was considered as the primary sampling unit (PSU). Each WA consisted of various census sectors. ${ }^{14}$ In each selected WA, five census sectors were randomly chosen (secondary sampling unit). Next, five corners of these census sectors were randomly selected for visitation. The variables of the sampling plan, strata and PSU were included in the data analysis.

The city of Belo Horizonte consists of 62 weighted areas (WA), containing a total of 2,563 census sectors. ${ }^{15}$ All sectors were included in the randomization process. Research assistants initiated the selection of women at each of the five randomly selected corners in each sector, guided by maps of the location. They went to each household and verified whether there were any Brazilian-born women of 40-65 years of age living in the home and whether they had at least
11 years of formal education. If there were eligible women living at that address, they were invited to participate in the study. If they agreed to participate, a questionnaire was left to be answered and a date was scheduled for the completed questionnaire to be collected. If the eligible women were not at home, they were contacted by telephone and, if they agreed to participate, the questionnaire was delivered to their home. The principal investigator telephoned the participants and confirmed completion of the questionnaires. Completed questionnaires were collected by a messenger, placed in an unlabeled envelope, and put into a sealed post-box to be delivered to the principal investigator. When questionnaires were delivered to the principal investigator, the weighted area and the education level (11 years of schooling) were noted to homogenize the response.

A total of 420 questionnaires were distributed. Forty-two women (10\%) refused to participate in the study. The reasons given by the women for not participating were: lack of time, that they did not feel comfortable answering the questions, or that their husbands did not want them to participate in the study. Thus, 378 questionnaires were filled out and delivered to principal investigator; of these, 315 (83.3\%) contained answers to all questions used to calculate the sexual dysfunction score. The delivered questionnaires that returned incomplete were not taken into consideration. Thus, 315 middle-aged women took part in the present study.

The questionnaire used in the study consisted of two parts. In the first part, the participants answered questions regarding their sociodemographic characteristics (age, marital status, ethnic group, income, schooling and paid employment), clinical characteristics (previous surgical history, body mass index, depression, arterial hypertension, diabetes, urinary incontinence, history of cancer, hot flashes, nervousness, insomnia, hormone therapy and self-perception of state of health), reproductive characteristics (menopausal status, number of pregnancies) and behavioral characteristics (physical activity, smoking and presence of sexual partner). Next, they answered questions about their sexuality.

The study protocol was conducted in accordance with the Helsinki Declaration and approved by the Internal Review Board of the institution.

\section{Evaluation of sexual dysfunction}

The instrument used to evaluate sexual dysfunction was based on the Short Personal Experiences Questionnaire (SPEQ) ${ }^{16}$ The original version of this instrument was made available by investigators at the University of Melbourne, Australia. The questionnaire was independently translated from its original English into Brazilian Portuguese by two translators fluent in both languages. Next, the two versions 
were compared and a final version was obtained with the approval of both translators. This version was then tested in a group of 50 Brazilian-born women of 40-65 years of age with 11 years or more of schooling. To ensure cultural equivalence, all questions that generated doubt were once again adapted and tested until the questionnaire was completely comprehensible to all women in the pilot group. A final version of the questionnaire in Brazilian Portuguese was thus obtained. All of the questions referred to the month prior to the interview.

\section{Dependent variable}

The variable sexual dysfunction was calculated from the mean of the sum of the scores of 1) sexual responsiveness, which evaluated pleasure in sexual activities (graded from 1 to 6 , where 1 reflected an absence of pleasure and 6 maximum pleasure), excitation (1-6) and orgasm (1-6); 2) frequency of sexual activities ( $1=$ never, $2=$ less than once a week; $3=$ once or twice a week, $4=$ several times a week, and $5=$ once a day or more); and 3 ) libido ( $1=$ it never took place, $2=$ it took place less than once a week, $3=i$ took place once or twice a week, $4=i t$ took place several times a week, $5=$ it took place once a day or more). A score $\leq 7$ was considered indicative of sexual dysfunction and a score $>7$ was considered indicative of no sexual dysfunction. ${ }^{16}$

\section{Independent variables}

Age was dichotomized into $<50$ years or $\geq 50$ years of age. Menopausal status was classified as premenopausal, perimenopausal or postmenopausal. Menopausal status was defined as premenopausal when the women had regular menstrual cycles or a menstrual cycle similar to the pattern that had been predominant throughout their reproductive life. Women were considered to be in perimenopause if they had menstrual cycles during the previous 12 months, but with some alterations in their menstrual pattern. Women were considered postmenopausal if their last menstrual period was at least 12 months prior to the interview. ${ }^{17}$ In women who been to hysterectomy, menopausal status was classified as follows: women aged 40-44 years who had regular menstruation prior to hysterectomy were considered to be premenopausal; women aged 45-48 years who had irregular menstruation prior to hysterectomy were considered to be in perimenopause; and women of more than 48 years of age or as well as those who had undergone hysterectomy with bilateral oophorectomy were considered to be postmenopausal, based on a previous report that the mean age at menopause in Latin America is 48.6 years. ${ }^{18}$ Marital status was dichotomized into married/ living with a partner, or other; ethnic group into white or non-white; schooling into 11 years or more than 11 years of formal education; family income into $\leq$ US $\$ 1300$ or > US $\$ 1300$ per month; physical activity into none $<3$ times a week or $\geq 3$ times a week; and number of pregnancies into $>2$ or $\leq 2$. Body mass index (BMI) was dichotomized into $<$ 25 or $\geq 25 \mathrm{~kg} / \mathrm{m}^{2}$. Paid employment was dichotomized into none/ $\leq 20$ hours per week or $>20$ hours per week. Smoking was dichotomized into never smoked or current/past smoker. The presence or absence (yes or no) of the following variables was also investigated: depression, arterial hypertension, diabetes, urinary incontinence, history of cancer, hot flashes, nervousness, insomnia and the presence of a sexual partner in the previous month. Hormone therapy was dichotomized into never used or current/past user. Self-perception of the state of health was classified as terrible/poor/average or good/ excellent.

\section{Statistical analysis}

A bivariate analysis was performed to evaluate sexual dysfunction as a function of the independent variables. The chi-square test was applied followed by Yates' correction or Fisher's exact test. ${ }^{19}$ Finally, Poisson multiple regression analysis was applied to the model to calculate the prevalence ratio (PR) and the respective $95 \%$ confidence intervals $(95 \% \mathrm{CI}) .{ }^{20}$ The backward criterion strategy was used to select the variables. ${ }^{21}$ For this analysis, the strata and the cluster/smallest geographical unit of the sampling plan were used. Stata software version 7.0 (Stata Corporation, College Station, Texas, USA) was used for the analysis. The criterion used for the inclusion of independent variables in multiple regression analysis consisted of a $p$-value of $<0.25$ in bivariate analysis or in a simple logistic regression. P-values $\leq 0.05$ were considered statistically significant.

\section{RESULTS}

In this sample, $46.7 \%$ of participants were 50 years of age or more; $65.9 \%$ were married or living with a partner; $70.8 \%$ reported having a sexual partner; $50.8 \%$ stated that they had more than 11 years of schooling; $59.5 \%$ had a family income $\leq$ US $\$ 1300 ; 51 \%$ had more than two children; and $33.5 \%$ reported practicing physical activity regularly, three or more times a week (data not presented as a table). The prevalence of sexual dysfunction was $35.9 \%$. The prevalence of sexual dysfunction among premenopausal women was $24.2 \%$, perimenopausal women $37.3 \%$ and postmenopausal women $45.3 \%$.

The 315 women who answered the five questions comprising the sexual dysfunction variable were compared to the 63 who failed to answer these questions. Women 
who were unmarried or not living with a partner $(\mathrm{p}<0.001)$ and those who reported hypertension $(\mathrm{p}=0.002)$ or urinary incontinence $(\mathrm{p}=0.036)$ were more likely to answer all questions contained in the section on sexual dysfunction.

In the bivariate analysis, women with greater probability of having sexual dysfunction (score $\leq 7$ ) had the following characteristics: they were in peri- or postmenopause $(\mathrm{p}=0.007)$, had a sedentary lifestyle $(\mathrm{p}=0.019)$, reported depression $(\mathrm{p}=0.003)$, arterial hypertension $(\mathrm{p}<0.002)$, diabetes $(p=0.046)$, hot flashes $(p=0.009)$, nervousness $(\mathrm{p}=0.048)$ or insomnia $(\mathrm{p}=0.003)$, and had a poor perception of their own health $(\mathrm{p}<0.002)$, (Table 1).

Multiple regression analysis showed that more advanced age $(\mathrm{PR}=1.04 ; 95 \% \mathrm{CI}: 1.01-1.07)$ and the presence of hot flashes $(\mathrm{PR}=1.37$; 95\%CI: 1.04-1.80) were significantly associated with sexual dysfunction. Conversely, women who felt well ( $\mathrm{PR}=0.68 ; 95 \% \mathrm{CI}$ : 0.52-0.88) and women with sexual partners (PR $=0.47$; 95\%CI: $0.34-0.65)$ were less likely to have a score of $\leq 7$ for sexual dysfunction (Table 2).

\section{DISCUSSION}

The objective of this study was to evaluate the prevalence of sexual dysfunction and to identify its associated factors in middle-aged, Brazilian-born women.

The profile of the population of the present study should be emphasized in view of the scarcity of population-based studies on female sexuality, particularly among middle-aged women.

In the present study, overall sexual dysfunction was evaluated in women with or without a sexual partner. In a study carried out in a US population, ${ }^{22}$ Kinsey (1948) showed that the search for sexual pleasure involves the mind and entire body of individuals, not only their genitals. Given women's greater longevity, it is very probable that many will grow old alone; however this does not imply the end of their sexuality or loss of their need for intimacy, touch and affection. $^{23}$

The use of an internationally recognized questionnaire, the SPEQ, ${ }^{16}$ which was adapted for use in Brazil, is another factor that deserves particular mention. As direct interviews on sexual activity during menopause may lead to constraints in responses, ${ }^{24}$ it was important for the questionnaire to be self-response and anonymous. Various measures were taken to ensure that the women selected would feel at ease to respond honestly to the questions. For instance, research assistants were selected who had a similar profile to that of the women in the study sample in order to encourage empathy, and reassurance was given to participants that all answers would remain confidential.
Table 1 - Variables associated with the sexual dysfunction (SPEQ score 57 ) of middle-aged women - Bivariate analysis

\begin{tabular}{|c|c|c|c|c|}
\hline Variable & $\mathrm{N}^{\mathrm{a}}$ & Score $\leq 7$ & Score $>7$ & p-value ${ }^{b}$ \\
\hline Menopausal status & & & & 0.007 \\
\hline Premenopausal & 99 & 24.2 & 75.8 & \\
\hline Menopausal transition & 110 & 37.3 & 62.7 & \\
\hline Postmenopausal & 106 & 45.3 & 54.7 & \\
\hline $\begin{array}{l}\text { Physical activity in the previ- } \\
\text { ous month }\end{array}$ & & & & 0.019 \\
\hline None $/<3$ times/week & 206 & 41.3 & 58.7 & \\
\hline$\geq 3$ times/week & 104 & 26.9 & 73.1 & \\
\hline Depression & & & & 0.003 \\
\hline No & 194 & 30.9 & 69.1 & \\
\hline Yes & 92 & 50.0 & 50.0 & \\
\hline High blood pressure & & & & $<0.002$ \\
\hline No & 224 & 30.8 & 69.2 & \\
\hline Yes & 78 & 52.6 & 47.4 & \\
\hline Diabetes & & & & 0.046 \\
\hline No & 289 & 34.6 & 65.4 & \\
\hline Yes & 16 & 62.5 & 37.5 & \\
\hline Hot flushes & & & & 0.009 \\
\hline No & 222 & 31.1 & 68.9 & \\
\hline Yes & 88 & 47.7 & 52.3 & \\
\hline Nervousness & & & & 0.048 \\
\hline No & 144 & 29.9 & 70.1 & \\
\hline Yes & 167 & 41.3 & 58.7 & \\
\hline Insomnia & & & & 0.003 \\
\hline No & 186 & 29.0 & 71.0 & \\
\hline Yes & 125 & 46.4 & 53.6 & \\
\hline $\begin{array}{l}\text { Self-perception of general state } \\
\text { of health }\end{array}$ & & & & $<0.002$ \\
\hline Terrible/poor/average & 127 & 47.2 & 52.8 & \\
\hline Good/excellent & 185 & 27.6 & 72.4 & \\
\hline
\end{tabular}

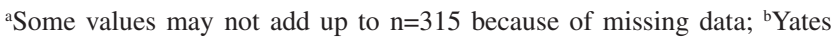
correction to chi-squared test.

Table 2 - Variables associated with sexual dysfunction (scores $\leq 7)$ in middle-aged women - Multiple analysis ${ }^{\mathrm{a}}$

\begin{tabular}{lccc}
\hline Variable & PR & $95 \%$ CI & p-value \\
\hline Age (years) & 1.04 & $1.01-1.07$ & 0.009 \\
Hot flushes (yes) & 1.37 & $1.04-1.80$ & 0.027 \\
$\begin{array}{l}\text { Sexual partner in previous month } \\
\text { (yes) }\end{array}$ & 0.47 & $0.34-0.65$ & $<0.001$ \\
$\begin{array}{l}\text { Self-perception of health status } \\
\text { (good/excellent) }\end{array}$ & 0.68 & $0.52-0.88$ & 0.007 \\
\hline
\end{tabular}

aPoisson regression; $\mathrm{PR}=$ prevalence ratio; $\mathrm{CI}=$ confidence interval 
In the present study, the prevalence of sexual dysfunction was $35.9 \%$, increasing from the pre- to the postmenopause. These data are in agreement with findings from other studies carried out in different populations. In a prospective observational study, Dennerstein et al ${ }^{3,25}$ also found that from the beginning to the latter phase of the menopausal transition, the proportion of women with sexual dysfunction increased from $42 \%$ to $88 \%$. In a study carried out in Chile, Castelo-Branco et al. ${ }^{26}$ found that $51.3 \%$ of sexually active women presented sexual dysfunction. Abdo et al. ${ }^{27}$ found at least one type of sexual dysfunction in $57.4 \%$ of women 41 years of age or older. Nevertheless, in our sample, multiple analysis showed no association between menopausal status and sexual dysfunction. One possible explanation for this finding may be that in women with a higher educational level, the percentage affected by sexual dysfunction is lower. ${ }^{27}$

Sexual dysfunction was not significantly associated with age, which was dichotomized into $<50$ years and $>50$ years for the bivariate analysis; however, in the multiple regression analysis, when the variable was considered in a continuous manner, the correlation between sexual dysfunction and increasing age was significant. In a previous study ${ }^{13}$ carried out in this same sample population, albeit with a more general evaluation of sexuality, a decline in sexuality as a function of increased chronological age was also found. A longitudinal cohort study carried out in Australia reported a significant negative effect of aging on the frequency of sexual activity, as well as on aspects of responsiveness (sexual excitation, pleasure and orgasm). ${ }^{3,25}$ The Women's International Study of Health and Sexuality, a multinational, cross-sectional study carried out in Europe and in the United States, reported a decline in all aspects of sexual function with aging. ${ }^{28}$ In a longitudinal study, Ford et al ${ }^{29}$ also reported that an increase in age was associated with poorer sexuality. Castelo-Branco et $\mathrm{al}^{26}$ evaluated 534 healthy, middle-aged Chilean women and found that the prevalence of sexual dysfunction increased from $22 \%$ in the 40-44-year old age-group to $66 \%$ in the $60-64$ year olds.

Hot flushes, depression, nervousness and insomnia were associated with scores $\leq 7$ for sexual dysfunction in the present analysis. These results are in agreement with those of previous studies in which depression was associated with difficulties in vaginal lubrication in women in some regions of the world, whereas stress was associated with inability to achieve orgasm. ${ }^{30}$ Other studies have also reported that psychological symptoms, stress and emotional problems may be related to a decline in sexual activity. ${ }^{31}$ It was also found that psychological symptoms were common in climacteric women and were associated with hot flashes. This observation connects psychological symptoms with the menopausal transition and suggests that their cause may be biological. ${ }^{32}$ Hot flashes are known to constitute a triggering factor for insomnia, which, in turn, leads to a reduction in energy and to depression, which has a negative effect on sexual function..$^{33}$

The women in the present sample who reported leading a sedentary lifestyle or who had a poor perception of their own health were more likely to be affected by sexual dysfunction. Other studies have reported similar findings. Greendale et $\mathrm{al}^{34}$ reported that an increase in physical activity and satisfaction with life were related to improved sexual function. Mental health, ${ }^{30,35}$ emotional well-being and positive self-image were associated with improved sexual function. . $^{30,35,36}$

On the other hand, additional studies have found correlations between chronic diseases and an increase in sexual dysfunction ${ }^{28,37}$ due to circulatory problems, ${ }^{38}$ neurological function, hormone balance or systemic health. ${ }^{39}$ It has been found that both an increase in systolic arterial pressure and the administration of beta blockers to treat hypertension may be detrimental to sexual function..$^{40}$ The present analysis shows that arterial hypertension was associated with the occurrence of sexual dysfunction, although the use of medication for hypertension was not evaluated in this study. Diabetes was another disease associated with sexual dysfunction. This finding is in agreement with other studies that reported that women with diabetes had a higher prevalence of sexual dysfunction compared to non-diabetic women. ${ }^{41,42}$

In the present study, women who had a sexual partner were less likely to have sexual dysfunction. This is consistent with other studies on middle-aged women conducted in different geographical locations, emphasizing the relevance of the sexual partner as a protective factor against sexual dysfunction. ${ }^{13,36,43}$ Nevertheless, previous studies have also described the importance of feelings for the partner with respect to sexuality. ${ }^{44}$ These data suggest the need to carry out further studies to investigate, in addition to the simple presence of a partner, the quality of relationship of these couples.

This study should be interpreted within the context of its limitations. The questionnaires that were returned incomplete were not taken into consideration in the evaluation of sexual dysfunction. The group composed of unmarried women or those not living with a partner and who reported hypertension or urinary incontinence, was associated with answering the entire block of questions concerning sexual dysfunction. Women with these characteristics who may have sexual dysfunction may be more motivated to answer all the questions.

The data, which include information on hypertension, psychological symptoms and the use of hormone therapy, 
were obtained by participant self-report. Although recall bias cannot be ruled out, previous studies using sef-reports suggest a high validity of health information, indicating that women with higher education levels provide more reliable data. ${ }^{45}$

\section{CONCLUSIONS}

Sexual dysfunction was found in more than one-third of women that were 40-65 years of age with 11 years or more of formal education.

Informing women, giving them the tools necessary to change their own lifestyle, and treating climacteric symptoms and existing comorbidities may lead to improved sexuality and, consequently, to a better quality of life. Future studies are required to evaluate the effects of hormones and other drugs on the sexuality of climacteric women.

\section{ACKNOWLEDGMENTS}

We would like to thank Professor Lorraine Dennerstein for providing us with the Short Personal Experiences Questionnaire (SPEQ) and for the literature that she kindly sent to our research group and the São Paulo Foundation for the Support of Research (FAPESP), for grant \# 04/10524-8.

\section{REFERENCES}

1. Kaiser FE. Sexual function and the older woman. Clin Geriatr Med. 2003;19:463-72.

2. Laumann EO, Paik A, Rosen RC. Sexual dysfunction in the United States: prevalence and predictors. JAMA. 1999;281:537-44.

3. Dennerstein L, Randolph J, Taffe J, Dudley E, Burger H. Hormones, mood, sexuality, and the menopausal transition. Fertil Steril. 2002;77:S42-8.
4. Dennerstein L, Lehert P, Burger H, Guthrie J. Sexuality. Am J Med. 2005; 118:59-63.

5. Nappi RE, Verde JB, Polatti F, Genazzani AR, Zara C. Self-reported sexual symptoms in women attending menopause clinics. Gynecol Obstet Invest. 2002;53:181-7.

6. Basson R. The female sexual response: a different model. J Sex Marital Ther. 2000;26:51-65. 
7. Nappi RE, Veneroni F, Verde JB, Polatti F, Fignon A, Farina C, et al. Climacteric complaints, female identity, and sexual dysfunctions. J Sex Marital Ther. 2001;27:567-76.

8. Avis NE, Zhao X, Johannes CB, Ory M, Brockwell S, Greendale GA. Correlates of sexual function among multi-ethnic middle-aged women: results from the Study of Women's Health Across the Nation (SWAN). Menopause. 2005;12:385-98.

9. Dennerstein L. Sexuality, midlife, and menopause. Menopause. 2008; $15: 221-22$

10. González M, Viáfara G, Caba F, Molina T, Ortiz C. Libido and orgasm in middle-aged woman. Maturitas. 2006;53:1-10.

11. Blumel JE, Bravo F, Recavarren M, Sarrá S. [Sexual function in postmenopausal women using hormone replacement therapy]. Rev Med Chil. 2003;131:1251-5.

12. Pedro AO, Pinto-Neto AM, Costa-Paiva LH, Osis MJ, Hardy EE. [Climacteric syndrome: a population-based study in Campinas, SP, Brazil]. Rev Saude Publica. 2003;37:735-42.

13. Valadares AL, Pinto-Neto AM, Osis MJ, Conde DM, Sousa MH, CostaPaiva L.Sexuality in Brazilian Women aged 40 to 65 years with eleven years or more of Formal Education: Associated factors. Menopause. 2008; 15: 264-69.

14. Instituto Brasileiro de Geografia e Estatística (Brazilian Institute of Geography and Statistics) - Brasil. Database per weighted area. Demographic census 2000. Results of sample \# 3106200. Available at: http://www.ibge.gov.br/lojavirtual/fichatecnica. php?codigoproduto=8481. Accessed March 6, 2004.

15. Instituto Brasileiro de Geografia e Estatística (Brazilian Institute of Geography and Statistics) - Brasil. Database per census sector. Demographic census 2000. Results of sample \# 3106200. Available at: http://www.ibge.gov.br/lojavirtual/fichatecnica. php?codigoproduto=7322. Accessed March 6, 2004.

16. Dennerstein L, Anderson-Hunt M, Dudley E. Evaluation of a short scale to assess female sexual functioning. J Sex Marital Ther. 2002;28:38997.

17. Soules MR, Sherman S, Parrott E, et al. Executive summary: Stages of Reproductive Aging Workshop (STRAW), Park City, Utah, July, 2001. Menopause. 2001;8:402-7.

18. Castelo-Branco C, Blümel JE, Chedraui P, Calle A, Bocanera R, Depiano E, et al. Age at menopause in Latin America. Menopause. 2006;13:70612 .

19. Altman DG. Practical statistics for medical research, 1st ed. Boca Raton, FL: Chapman \& Hall/CRC; 1999.

20. Johnson RA, Wichern DW. Applied Multivariate Statistical Analysis, 1st ed. Upper Saddle River, NJ: Prentice Hall; 1982.

21. Barros AJ, Hirakata VN. Alternatives for logistic regression in crosssectional studies: an empirical comparison of models that directly estimate the prevalence ratio. BMC Med Res Methodol. 2003;3:21.

22. Kinsey AS, Pomeroy WB, Martin CR. Sexual behavior in the human male. Philadelphia: W.B. Saunders; 1948.

23. Kaiser FE. Sexual function and the older woman. Clin Geriatr Med. 2003; 19:463-72.

24. McCoy NL. Female sexuality during age. In: Hof PR, Mobbs CV, editors. Functional neurobiology of aging. San Diego: Academic Press; 2001. pp. 769-79.
25. Dennerstein L, Guthrie JR, Hayes RD, DeRogatis LR, Lehert P. Sexual function, dysfunction, and sexual distress in a prospective, populationbased sample of mid-aged, Australian-born women. JSM. 2008;5(8) 00-00 (In press).

26. Castelo-Branco C, Blumel JE, Araya H, Riquelme R, Castro G, Haya $\mathrm{J}$, et al. Prevalence of sexual dysfunction in a cohort of middle-aged women: influences of menopause and hormone replacement therapy. J Obstet Gynaecol. 2003;23:426-30.

27. Abdo CH, Oliveira WM Jr, Moreira ED Jr, Fittipaldi JA. Prevalence of sexual dysfunctions and correlated conditions in a sample of Brazilian women--results of the Brazilian study on sexual behavior (BSSB). Int J Impot Res. 2004;16:160-6.

28. Hayes RD, Dennerstein L, Bennett CM, Koochaki PE, Leiblum SR, Graziottin A. Low sexual desire, distress due to low sexual desire and aging (abstract). In: International Society for the study of Women's Sexual Health. Annual Meeting Program Book, Atlanta, Georgia, October 28-31, 2004. Schaumberg, IL: ISSWSH, 2004:36.

29. Ford K, Sowers M, Crutchfield M, Wilson A, Jannausch M. A longitudinal study of the predictors of prevalence and severity of symptoms commonly associated with menopause. Menopause. 2005;12:308-17.

30. Laumann EO, Nicolosi A, Glasser DB, Paik A, Gingell C, Moreira E, et al. Sexual problems among women and men aged 40-80 y: prevalence and correlates identified in the Global Study of Sexual Attitudes and Behaviors. Int J Impot Res. 2005; 17:39-57.

31. Mishra G, Kuh D. Sexual functioning throughout menopause: the perceptions of women in a British cohort. Menopause. 2006;13:88090 .

32. Blümel JE, Castelo-Branco C, Cancelo MJ, Córdova AT, Binfa LE, Bonilla HG, et al. Relationship between psychological complaints and vasomotor symptoms during climacteric. Maturitas. 2004;49:205-10.

33. Ohayon MM. Severe hot flashes are associated with chronic insomnia Arch Intern Med. 2006;166:1262-8.

34. Greendale GA, Hogan P, Shumaker S. Sexual functioning in postmenopausal women: the Postmenopausal Estrogen/Progestin Interventions (PEPI) trial. J Womens Health. 1996;5:445-58.

35. Bancroft J, Loftus J, Long JS. Distress about sex: a national survey of women in heterosexual relationships. Arch Sex Behav. 2003;32:193208.

36. Dennerstein L, Lehert P. Women's sexual functioning, lifestyle, mid-age, and menopause in 12 European countries. Menopause. 2004;11:77885 .

37. Safarinejad MR. Female sexual dysfunction in a population-based study in Iran: prevalence and associated risk factors. Int J Impot Res. 2006;18:382-95.

38. Goldstein I, Berman JR. Vasculogenic female sexual dysfunction: vaginal engorgement and clitoral erectile insufficiency syndromes. Int J Impot Res. 1998;10:S84-90.

39. Walsh KE, Berman JR. Sexual dysfunction in the older woman: an overview of the current understanding and management. Drugs Aging. 2004;21:655-75.

40. Doumas M, Tsiodras S, Tsakiris A, Douma S, Chounta A, Papadopoulos A, et al. Female sexual dysfunction in essential hypertension: a common problem being uncovered. J Hypertens. 2006;24:2387-92. 
41. Enzlin P, Mathieu C, Van den Bruel A, Bosteels J, Vanderschueren D, Demyttenaere K. Sexual dysfunction in women with type 1 diabetes: a controlled study. Diabetes Care. 2002;25:672-7.

42. Schiel R, Müller UA. Prevalence of sexual disorders in a selection-free diabetic population (JEVIN). Diabetes Res Clin Pract. 1999;44:11521.

43. Gracia CR, Freeman EW, Sammel MD, Lin H, Mogul M. Hormones and sexuality during transition to menopause. Obstet Gynecol. 2007;109:831-40.
44. Valadares AL, Pinto-Neto AM, Osis MJ, Conde DM, Sousa MH, CostaPaiva L.The Sexuality of Middle-aged Women with a Sexual Partner: a Population-based Study, Menopause. 2008;15:706-13.

45. Okura Y, Urban LH, Mahoney DW, Jacobsen SJ, Rodeheffer RJ. Agreement between self-report questionnaires and medical record data was substantial for diabetes, hypertension, myocardial infarction and stroke but not for heart failure. J Clin Epidemiol. 2004;57:1096-103. 